\title{
The Teaching Evaluation as a Means of Control over the Java Training Process
}

\author{
Xiao-Wan ZHU ${ }^{1,2, a}$, Xu-Fu PENG ${ }^{1,3, b,{ }^{*}}$, Hui YAN ${ }^{1, c}$ \\ ${ }^{1}$ College of Computer Science and Technology, Hubei Normal University, Huangshi \\ 435002, China. \\ ${ }^{2}$ College of Educational Science, Hubei Normal University, Huangshi 435002, China. \\ ${ }^{3}$ College of Arts and Science, Hubei Normal University, Huangshi 435002, China. \\ a995387174@qq.com, ${ }^{\mathrm{b}}$ pengxufu@163.com, ${ }^{\mathrm{c}} 714576810 @ q q . c o m$ \\ ${ }^{*}$ Corresponding author
}

Keywords: Java course, Teaching reflection, Process control, Multiple teaching evaluation.

\begin{abstract}
Concerning the problems in the task-driven and project-driven teaching methods, the teaching evaluation is introduced in our paper to perfect the control over the teaching process. Before the class starts, the pre-class tests and learning contracts are additionally performed to better plan the students themselves; During the class likewise, the pluralistic evaluation session and stage reflection tables are to enable the students and teachers more interactions, reflections and continuous adjustment of their own plans; in the final parts of class, dynamic evaluation integrated into the evaluation of the project is to prompt effective teaching and pragmatic learning. The process files are adequately collected so as the learning process can be recorded, observed, summarized and evaluated.
\end{abstract}

\section{Introduction}

With the advancement of science and technology, more and more students are growing passionate for Java training. Since Java training courses are dramatically practical, nearly all the faculties are applying task-driven and project-driven teaching methods. Suitable as these two teaching methods may be in Java teaching, there are still some problems coexisting with them. The following is to control the process of teaching course by means of teaching evaluation.

\section{Problems}

The Java course requires from the students several months of training altogether, the content and process of which are generally as follows (see fig 1).

There are several problems in content and process.

First, through the overall analysis of the teaching content, we discover that some of them is moderately simple, which mostly targets on login and registration cases without any expansion or enrichment of the related cases. The teacher's teaching content is so much simple as to fail to keep with the real projects. The comparison of the textbooks published in these years has found very little or even nothing changed. So long may have the classical cases in the textbooks been around, nevertheless, they may not necessarily applicable to various types of specific projects, say, the teaching document being too old, cannot resolve the problems that error would occur operating the old program by the upgraded software. 


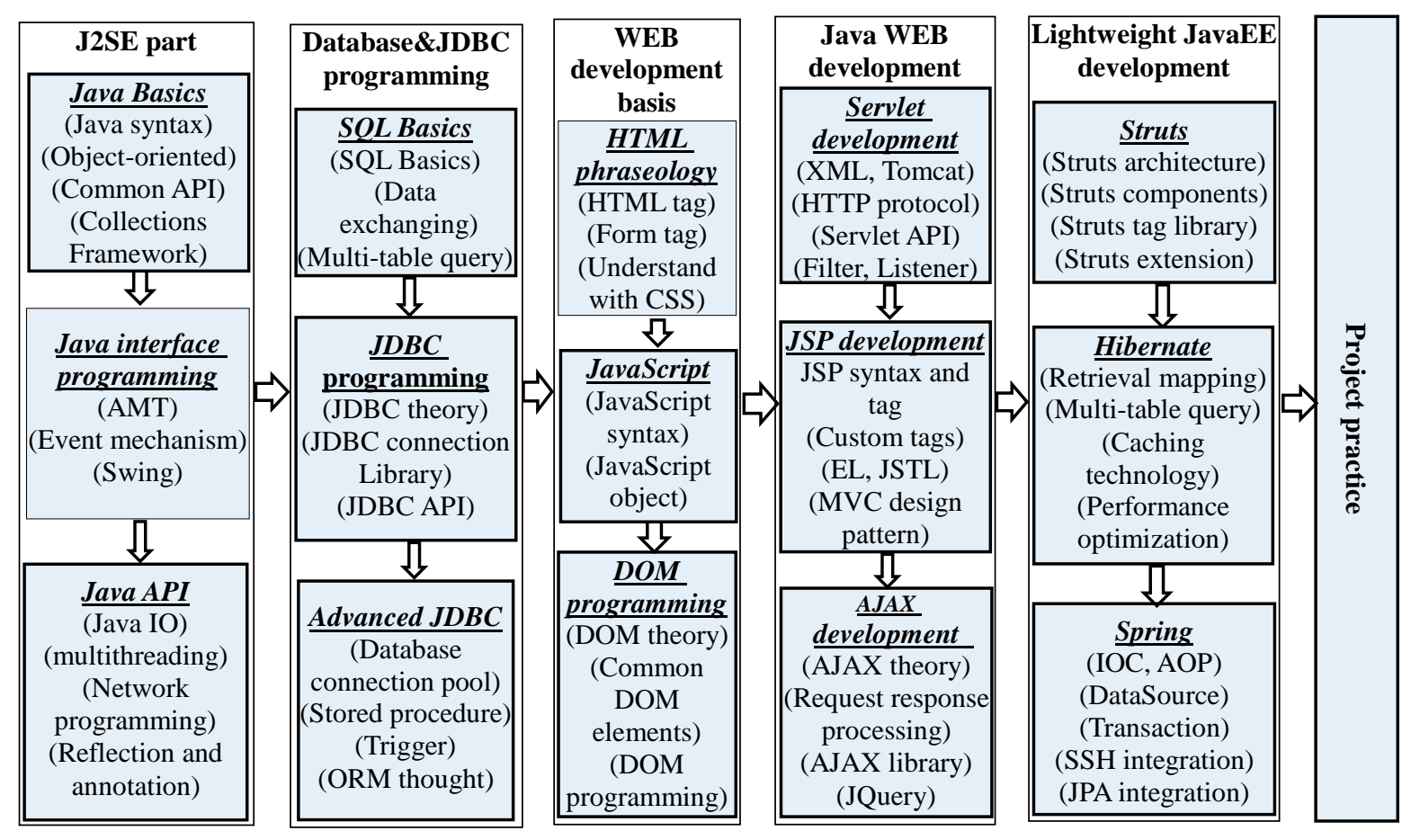

Fig 1 Java training course teaching content flow chart

Second, the teacher's process of teaching develops from simple to deep according to the teaching materials, and the time of lecturing depends on how difficult the material is. It tends to neglect such information as the student's absorption of the materials and their possible need for assistance.

Third, while the project-driven teaching methods is being conducted by some teachers, some students demonstrate inactive participation, which could be attributed to students' different levels of knowledge and their expertise, as well as the project selection and implementation process failing to effectively capture the interests of different students. Coupled with inadequate supervision, it is very likely to give rise to the "free ride" in the project $^{[1]}$.

Forth, the teacher's previous theoretical teaching could not reconcile with the implementation of specific projects.

Through observation of the entire teaching process of the Java training course, we predicate on java teaching characteristics to introduce teaching evaluation in the teaching process with the aim to solve such problems and prompt teaching effectiveness.

\section{Improve pre-class teaching implementation}

\section{Pre-test}

Before the Java training courses commence, the teacher would test the students with a paper developed by himself so as to understand the knowledge level of each student, based on which the teacher could draw up a teaching plan suitable for the majority of the students. Adding a test before class on the one hand, is to allow the students more aware of themselves and on the other hand, to help with the teacher's design of teaching. 


\section{Learning contract}

The learning contract jointly designed by the student and the teacher defines the student's learning objectives, the method for achieving the learning objectives, the time for the learning activity, and the criteria for evaluating the learning activity ${ }^{[2]}$. Before class, teachers would introduce the preliminary plan of teaching, course content of the whole training process, the key and difficult points of each part, as well as the learning period in total and in each part respectively. What follows is, to request that each student write their own learning plan and submit to the teachers. Lastly, confirm the teaching plan to be implemented.

The characteristic of learning contract evaluation is that the students control the whole learning activities. It not only satisfies the needs of the individual development of learners, but also helps learners monitor and evaluate their own learning efficacy according to the contract, maintain positive self-discipline and stimulate students' learning motivation and learning enthusiasm.

\section{Improve classroom teaching}

\section{Adding diversified evaluation to classroom teaching}

From the teaching process figure, it can be found that the entire training course from the J2SE part to the lightweight JavaEE development is carried out in such a way as first with quantities of theoretical then followed by practice. Most teachers adopt task-driven teaching method, trying to be task-driven and take some example as the forerunner. Then they put forward questions to guide students to think, so that students can master the teaching content through learning and doing. Eventually the teaching goal is achieved and students' ability to analyze and solve problems is developed.

Because of the particularity of Java training course, the absorption of knowledge can be more clearly manifested in the program. Nevertheless, writing a program requires multiple sorts of knowledge, the accumulation of which requires a certain amount time of teaching. If the teacher wants the students to summarize the acquired knowledge every day, the tasks for the students can only be after-school homework. With time being finite, teachers would first check students' after-school assignments on the second day, and then spend a short period of time lecturing concerned about these problems. If the teacher wants to catch up with the teaching progress, the after-school homework would only be suspended for a period of time. In this process, both teachers and students are involved in the teaching task though, the teachers solely struggle to get the students to participate in the study and make themselves as clear as possible. It remains uncertain as to whether or not the students have achieved mastering and applying the knowledge. Students study during the day and do homework at night. The lazy students, who feel overwhelming pressure from learning would inevitably cheat in the homework. consequently, it is very likely for the teachers to only learn part of students' performances in after school homework ${ }^{[3]}$.

In response to these problems, we propose with two aims to leave 10 minutes for evaluation at the end of the teaching every day. First, the students communicate, discuss, and summarize with each other the strengths and weaknesses of the class teaching and their inability to understand what the teachers have lectured. Then the student can make a literal evaluation of the teacher. Students who are uncomfortable in this way could alternatively submit to the teachers their comments anonymously. Second, teachers review and summarize the teaching and students' study on the same day. where the students perform well, the teachers give timely 
affirmation and praise. where the students do not, the teachers would also criticize them in person and raise some suggestions.

The combination of oral evaluation, paper(anonymous) evaluation and mutual evaluation, on the one hand, is conducive to finding and resolving problems, adjusting teaching time and methods in time. Changes built up little by little over the years will gradually make the teaching plan more suitable for both teachers and students. The teachers' teaching would go better along with the students' studying, thus the teaching efficiency is improved. On the other hand, it will help to strengthen the communication between students and teachers, and facilitate intimacy among class members ${ }^{[4]}$.

\section{Stage reflection table}

The structure of the teaching content of Java training course is as follows: the entire project is composed of every module, which then are of little units. The multiple evaluations in the previous stage are designed for slight moderation of teaching so that teachers and students can get along more smoothly. However, it is difficult to control the overall teaching process, which gives rise to the stage reflection table at this time.

After completing a module of Java course, the students would generally take an test, through which they would be aware of how well they have learned at this stage. In the meanwhile, the teachers would develop reflective form for the students according to their performance. The reflection form, which could be designed ahead of time, consists of series of questions or evaluation items. It can enable learners to understand the difference between the fulfillment of the learning task and the target, effectively prompt the learner's reflection and enhance the student s ability of introspection and self-learning.

The reflective table for evaluation served as a learning scaffold is provided by the teachers to enable the students thoroughly aware of what they should learn. It is even more of a self-evaluation tool, which can effectively cultivate and improve the students' reflective skills and meta-cognitive ability.

\section{Improving the teaching implementation process of the project}

\section{Be demanding on the quality of the project}

Whenever in the class practice, after - class tasks or project teaching, most of the time students are required to practice programming on their own, for which the project-driven method is best suite. Project-driven teaching method is a teaching activity that both teachers and students are involved in a complete project together. A properly selected project is assigned to the student and left to be processed by themselves ${ }^{[5]}$. Through the implementation of the project, the students can grasp the whole procedure and the basic requirements of each stage, and can as well make an authentic product by the end of the project. exquisite-quality projects require very tough supervision. Henceforth, the following needs to be paid heed to:

First, in the actual practicing stage of the project, the selected project should be of moderate difficulty, which can not only test the students' basic ability, but also can improve the students through their critical thinking and extra learning.

Second, at the same stage, although the same project would be completed by each group, as long as the overall designs and the functions of the products are controlled to be almost non-distinctive, it would be of great diversity as to the design of the front-end interface of the product and the means to fulfill its function due to the different students' ideas. It can create a 
competitive and cooperative learning atmosphere, which is beneficial for the discussions between students, reflections upon themselves and mutual improvement.

Third, in grouping, the instructor should take into the fullest account, the complexity of the project, the scheduled completion time, the students' knowledge and so forth, to control the size of each group.

Forth, when the members of each group is confirmed, the specific assignment undertaken by each member would be freely discussed and then be confirmed by the instructor, to guarantee the fair assignment, definite target and the moderately difficulty of the project for each group member

Fifth, after grouping is finished, the teacher would inform the students that when the project is completed, each group shall appoint representatives picked up by drawing lots to demonstrate about their achievement. The task targets on creation of the students' awareness that each member may be chosen as the representative of the group. It can not only push the students to complete their own functional modules and grasp the overall situation, but also drives the students to actively communicate with their partners.

Sixth, the teachers would urge students to finish the project timely according to the assignment and frequently check the completing progress of the project. Also, the instructor would teach students in accordance with their aptitude in case of "free riding".

\section{Integrating dynamic evaluation into project evaluation}

In reality, since the students complete the project in groups, the teaching evaluation of the project can only reflect upon the group performance. Integrated with dynamic assessment, progress of every student can be made. when the project is completed, each group would appoint a representative to demonstrate their project on the stage to the teacher and the whole class. The teacher would promptly remind group representatives of what should be included in the demonstration, such as the main functions of the product, whether the product system is completed and can operate normally, what modules each member of the group is responsible for, the introduction of all the small functional modules according to the completing progress of each member, the technology applied to complete this module task and the difficulties encountered in completing the project. Not until the students of other groups have illustrated their comments and opinions would the teacher then put forward his own evaluations and suggestions, which comes after each student representative finishes demonstration. when all the group members end up demonstration, the teachers would then do the summary, praising for each group's advantages, giving guidance to the deficiencies and explaining the mistakes made by all students. Finally, the students were required to take a post-test, that is the students were asked to independently complete another test which is as much difficult as the previous one.

Integrating dynamic evaluation into project evaluation can create two advantages. First the role of the students can be transferred from the object to the subject of evaluation. It can also promote the teachers' self-evaluation, peer evaluation and cooperative evaluation. The self-evaluation of group individual allows students to judge their own learning and peer evaluation between groups allows students to evaluate each other's projects. The students can develop some important cognitive skills and critical thinking ability by observing how peers solve problems. The evaluation of teacher-student cooperation can promote students to grasp the work of others. By comparison with their own related work, their learning motivation could be stimulated to a great extent. Second, a great deal of interaction thus comes into being between the subject and the object of the evaluation. Combining evaluation and teaching, the 
individualized diagnosis, evaluation and teaching remedy can come true.

\section{Using Portfolio Assessment to Monitor Teaching Process}

Portfolio evaluation is an objective and comprehensive evaluation of the object predicated on the portfolio, a collection of learning works which is collected by students under the guidance of teachers, reflecting the students' efforts and progress and learning achievements. It manifests the development of a student's skills in a period of time and a particular field.

The Java training course is very pragmatic. Students can make a systematic work with every module of java courses they have learned. Teachers should instruct the students to complete the work and keep it recorded before such documents and works as tests, papers, and study contracts should be collected in a chronological order. The comparative analysis of these documents can reveal how hard the students have studied, what progress they have made and what needs to be improved, through which students can introspect in time about themselves and improve their own learning methods, and the teachers can also adjust their teaching method.

\section{Conclusion}

Teaching evaluation is not an isolated stage or behavior, but one which is closely associate with the whole teaching process and can provide formative evaluation and feedback for each stage of the process. Adding appropriate teaching evaluation to the Java training course can: in terms of teaching, promote the teaching plan to be developed by the teachers and students together, carefully implemented and continually improved; in term of emotional communication, facilitate the students' interest in learning, strengthen the communication among students and cooperation between students and teachers and enhance the cognition of each other; in term of trace management, help the observation and record of students' learning behavior, students' self-reflection and improvement, teachers' track and reliance on the students' learning and the realization of truly achieving the purpose of teaching according to their aptitude and deficiency making up.

\section{Acknowledgements}

This research was supported by an innovative team of excellent young-middle-aged, universities in Hubei province (T201430), Hubei province education science "twelfth five-year" plan project (2013B112), Hubei natural science foundation youth project (2017CFB307), the school-level course construction project of case teaching for graduate students in 2017(20170117).

\section{References}

[1] Zhao Yiding, Gou Ximei, Di Heng. An Improved Project-Driven Teaching Method Applied in Software Testing Courses[J]. Computer Engineering\&Science,2016.11, 38(1):112-116.

[2] Zhang Wenqiang. Establishing Teacher's Classroom Teaching Evaluation System to Promote Students' Development[J]. China Higher Education,2013.10,38(1):37-39. 
[3] Li Ning. Application of Project-Driven Teaching Method in Computer Network Experiment Teaching in Colleges and Universities[J].Electronic Test,2016(10):98.

[4] Wang Shuang. Project-driven Stereoscopic Teaching Resource System Construction Based on Java Course[J]. Education and Vocation,2013.9,27(22):138-140.

[5] Tang Hairong, Li Xihui. Project-driven teaching reform of Java programming[J]. Education and Vocation, 2012.2,6(029):140-142. 